\title{
Damage Monitoring and Analysis of the Structure Effect on Strength of Composite Laminates
}

\author{
Chia-Chin Chiang, Liren Tsai, and Vu Van Thuyet \\ Kaohsiung University of Applied Sciences, 414 Chien Kung Road, Sanmin District, Kaohsiung City 80778, Taiwan \\ Correspondence should be addressed to Vu Van Thuyet; thuyetoto70@gmail.com
}

Received 25 September 2014; Accepted 12 December 2014

Academic Editor: Mo Li

Copyright ( $) 2015$ Chia-Chin Chiang et al. This is an open access article distributed under the Creative Commons Attribution License, which permits unrestricted use, distribution, and reproduction in any medium, provided the original work is properly cited.

\begin{abstract}
Carbon fiber reinforced polymer (CFRP) composite materials have been widely used in industries in recent years. The design of composite structures, and open-holes for joining are also widely used. Understanding of open-hole behavior is very necessary for the design of complex structures. In this paper, the initial damage, progressive damage analysis, and the effect of structure on strength of composite laminates are investigated. Based on Hashin's criteria, three-dimensional model of composite laminates containing a central open-hole is developed. The model is conducted by finite element analysis, commercial Abaqus software to simulate the whole process of initial damage, propagation of damage, and analysis of the effect of a few structures on strength of composite laminates containing open-hole.
\end{abstract}

\section{Introduction}

Composite materials have been extensively used in engineering and become an important material in aeronautic, automotive, and astronautic structures. There are many different shapes fabricated from composite structure in that kind of open-holes which are typical. During the using time, stress concentrations will appear around the holes and the surrounding areas. This is a phenomenon causing accumulation of damage and decreasing the strength of composite structures. The primary consideration of the structure is the evaluation of its load carrying capacity. Because analyzing stress, failure, and damage's structure is the best method used, in this work the composite laminates containing a central open-hole subjected to tension are investigated. Many previous studies about the damage of the composite material have been introduced [1-3]. There are some fracture-mechanistic models that are proposed to study propagation crack in composite laminates with an openhole. The propositions were significantly studied by previous researchers [4-11]. The authors developed a two-dimensional progressive damage model considering three different failure modes to predict the accumulation of damage and the strength of the composite laminates containing unloaded holes and loaded holes by integrating failure criteria of Yamada-Sun and Hashin. Although the failure of the plies was evaluated, the delamination of the composite structures was not considered in these analyses. The model needed the ply orientation of the laminates which must be symmetric with respect to the middle plane of the plate. Two-dimensional model cannot accurately analyze stress around open-holes. The layer orientations and delamination as well as damage of the composite laminates can be solved by three-dimensional finite element method with the commercial Abaqus. Therefore, the objective of this investigation is to predict the initial damage, progressive damage analysis, and the effect of a few structures on strength of composite laminates.

\section{Materials and Methods}

2.1. Progressive Damage Analysis. In this study, in order to predict the initial damage, progressive damage analysis and the effect of a few structures on strength of composite laminates are investigated. Based on Hashin's failure criteria and numerical model are presented as follows.

2.1.1. Damage Initiation. The onset of damage in Abaqus is detected by Hashin and Rotem initial damage criteria in 


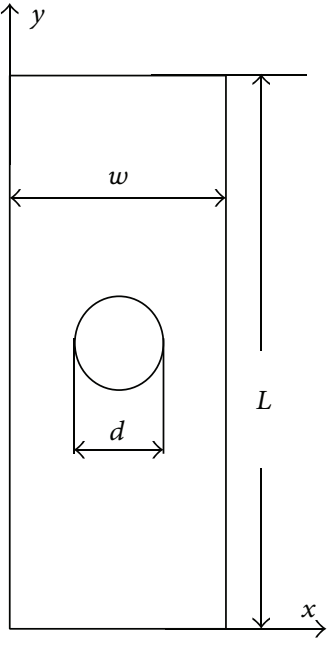

(a)

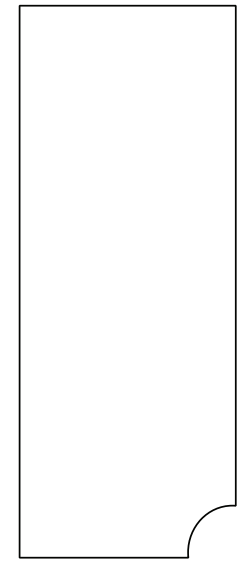

(b)

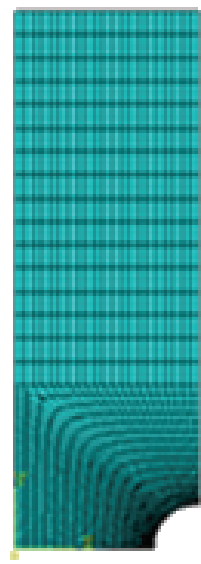

(c)

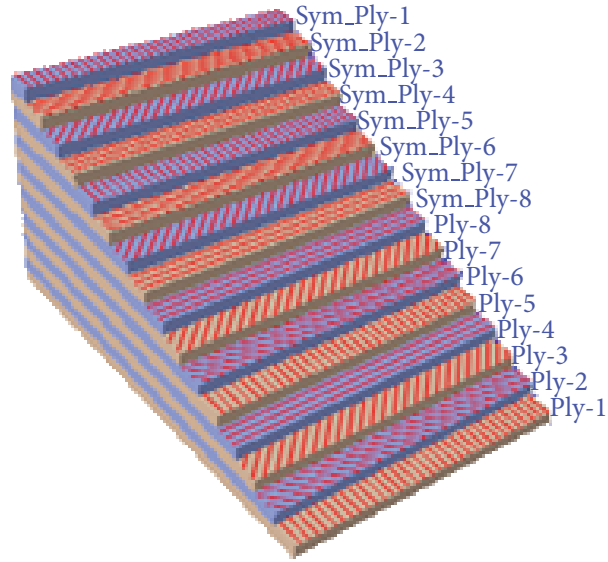

Lay-up: "composite lay-up-1" total thickness 2.616000. Plot of plies 1 to 16 , of 16

Figure 1: Illustrations of the basic geometry of the lamina (0/45/-45/90/0/45/-45/90)s containing central hole. (a) is the dimensional model, (b) is a quarter the model, and (c) is mesh used for analysis.

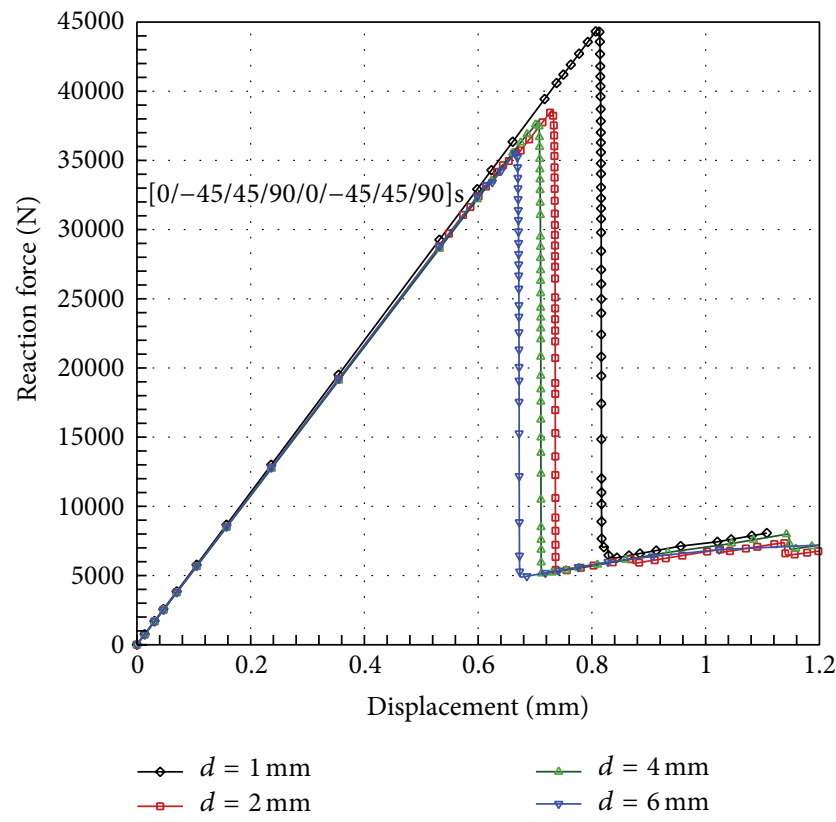

Figure 2: Comparison of load and displacement curves of $(0 / 45 /-45 / 90 / 0 / 45 /-45 / 90)$ s with different diameter holes.

terms of apparent (Cauchy) stress " $\sigma$," which is calculated by progressive damage analysis code. Damage initiation refers to the onset of stiffness degradation at a material point $[2,12]$. The consideration of damage laminates by Hashin's criteria in four cases is assumed to be uncoupled as follows:

fiber tension $\left(\sigma_{11} \geq 0\right)$

$$
F_{\mathrm{ft}}=\left(\frac{\sigma_{11}}{X^{t}}\right)^{2}+\alpha\left(\frac{\sigma_{12}}{S^{L}}\right)^{2}=1 \quad \text { where } 0 \leq \alpha \leq 1 \text {, }
$$

TABLE 1: Mechanical properties of CFRP T300/134-C.

\begin{tabular}{lccc}
\hline$E_{1}(\mathrm{GPa})$ & $E_{2}(\mathrm{GPa})$ & $G_{12}(\mathrm{GPa})$ & $\nu_{12}$ \\
\hline 146.8 & 11.4 & 6.1 & 0.3 \\
\hline$G_{L}(\mathrm{~N} / \mathrm{mm})$ & $G_{L}(\mathrm{~N} / \mathrm{mm})$ & $G_{T}(\mathrm{~N} / \mathrm{mm})$ & $G_{T}(\mathrm{~N} / \mathrm{mm})$ \\
\hline 89.83 & 78.27 & 0.23 & 0.46 \\
\hline$X^{t}(\mathrm{GPa})$ & $X^{c}(\mathrm{GPa})$ & $Y^{t}(\mathrm{GPa})$ & $Y^{c}(\mathrm{GPa})$ \\
\hline 17.3 & 13.79 & 6.65 & 2.682 \\
\hline$S^{T}(\mathrm{GPa})$ & $S^{L}(\mathrm{Ga})$ & & \\
\hline 0.5807 & 0.5807 & & \\
\hline
\end{tabular}

fiber compression $\left(\sigma_{11}<0\right)$

$$
F_{\mathrm{fc}}=\left(\frac{\sigma_{11}}{X^{c}}\right)^{2}=1
$$

matrix tension and/or shear $\left(\sigma_{22} \geq 0\right)$

$$
F_{\mathrm{mt}}=\left(\frac{\sigma_{22}}{Y^{t}}\right)^{2}+\left(\frac{\sigma_{12}}{S^{L}}\right)^{2}=1
$$

matrix compression $\left(\sigma_{22}<0\right)$

$$
F_{\mathrm{mc}}=\left(\frac{\sigma_{22}}{2 S^{T}}\right)^{2}+\left[\left(\frac{Y^{c}}{2 S^{T}}\right)^{2}-1\right] \frac{\sigma_{22}}{Y^{c}}+\left(\frac{\sigma_{12}}{S^{L}}\right)^{2}=1,
$$

where $\sigma_{11}, \sigma_{22}$, and $\sigma_{12}$ are the components in-plane longitudinal, transverse, and shear stress; $X^{c}, X^{t}$ are the compressive and tensile strength in the fiber direction; $Y^{c}, Y^{t}$ are the compressive and tensile strength in the matrix direction; $S^{T}$, $S^{L}$ are the transverse and longitudinal shear strength; and $\alpha$ determines the contribution of the shear stress to the fiber tensile criterion. To obtain the model proposed by Hashin and Rotem, it set $\alpha=0$ and $S^{T}=1 / 2 Y^{c} . F$ is the loading 


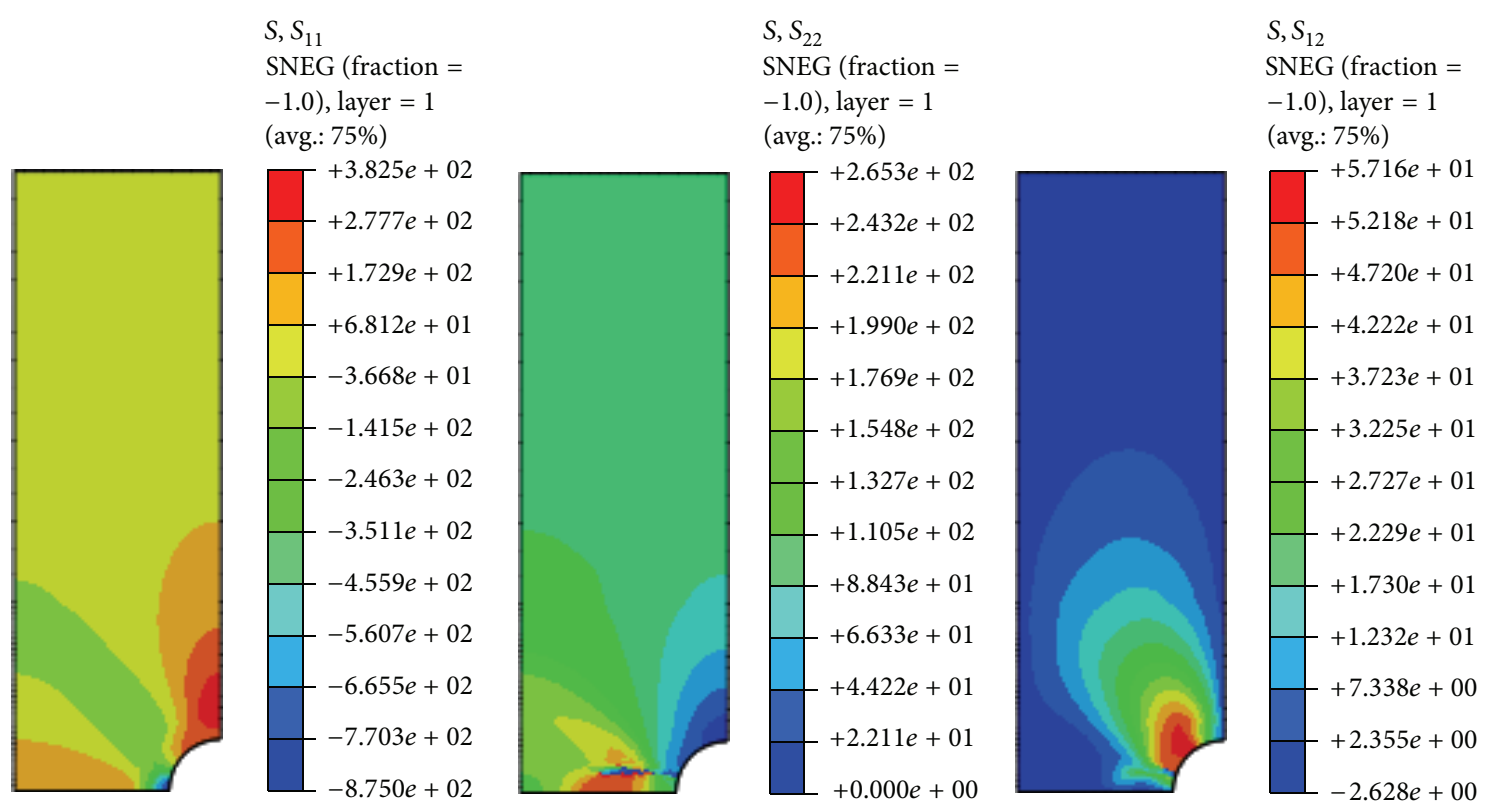

FIGURE 3: Stress $S_{11}, S_{22}$ and $S_{12}$ at integration points and stress concentration around open-hole.

functions for different failure mechanisms adopted in the form of Hashin's criteria. These indexes $F_{\mathrm{ft}}, F_{\mathrm{fc}}, F_{\mathrm{mt}}$, and $F_{\mathrm{mc}}$ indicated whether a damage initiation criterion in a damage model has been satisfied or not. Damage initiation occurs, when any one of the four indices exceeds 1 . The effect of damage is taken into account with reducing the values of the stiffness coefficients $[2,12]$ as follows:

$$
\begin{gathered}
\sigma=C \cdot \varepsilon \\
C=\frac{1}{D}\left[\begin{array}{ccc}
\left(1-d_{f}\right) E_{1} & \left(1-d_{f}\right)\left(1-d_{m}\right) v_{21} E_{1} & 0 \\
\left(1-d_{f}\right)\left(1-d_{m}\right) \nu_{12} E_{2} & \left(1-d_{m}\right) E_{2} & 0 \\
0 & 0 & D\left(1-d_{s}\right) G_{12}
\end{array}\right],
\end{gathered}
$$

where represents a tensor double contraction and damaged stiffness is given by

in which

$$
\begin{gathered}
D=1-\left(1-d_{f}\right)\left(1-d_{m}\right) v_{12} v_{21}, \\
d_{s}=1-\left(1-d_{\mathrm{ft}}\right)\left(1-d_{\mathrm{fc}}\right)\left(1-d_{\mathrm{mt}}\right)\left(1-d_{\mathrm{mc}}\right),
\end{gathered}
$$

where $\sigma$ is the apparent stress, $\varepsilon$ is the strain, $C$ is the damaged stiffness matrix, $E_{1}, E_{2}$ are the moduli in the fiber direction and perpendicular to the fiber, respectively, $G_{12}$ is the shear modulus, $v_{12}$ and $v_{21}$ are Poisson's ratios, $d_{\mathrm{ft}}, d_{\mathrm{fc}}, d_{\mathrm{mt}}, d_{\mathrm{mc}}$, and $d_{s}$ are damage variables of the fiber, matrix, and shear damage, in tension and compression, respectively. The shear damage variable is not independent but is given by (6) in terms of the remaining damage variables.

The variables damages $d_{\mathrm{ft}}, d_{\mathrm{fc}}$ and $d_{\mathrm{mt}}, d_{\mathrm{mc}}$, which characterize fiber and matrix damage in tension and compression, corresponding to the four damage initiation modes are represented in (1) (4). $X^{c}, X^{t}, Y^{c}, Y^{t}, S^{T}$, and $S^{L}$ are six values of the strength. In this work, in order to predict damage initiation, progressive damage analysis, and the effect of structure on strength of composite laminates accurately, the values of strength of CFRP T300/134-C material are used [3]. The mechanical properties of this material are listed in Table 1.

2.1.2. Numerical Models. In this study, the theoretical basis of the three-dimensional shell progressive damage approach is introduced. The geometry of the composite laminates containing a central open-hole is illustrated in Figure 1(a). Considering the symmetry of the composite laminates model and reducing the time of calculation, only one-quarter of the composite laminate is used in this study, as shown in Figure 1(b). The model composite lay-up built by Abaqus software and that has been meshed to obtain the best accuracy, using higher element density at the hole. The remaining parts of the model have been modeled using a coarse mesh with bigger elements to reduce the required computational time. The meshed model is shown in Figure 1(c). The boundary condition and loading are performed in commercial Abaqus 

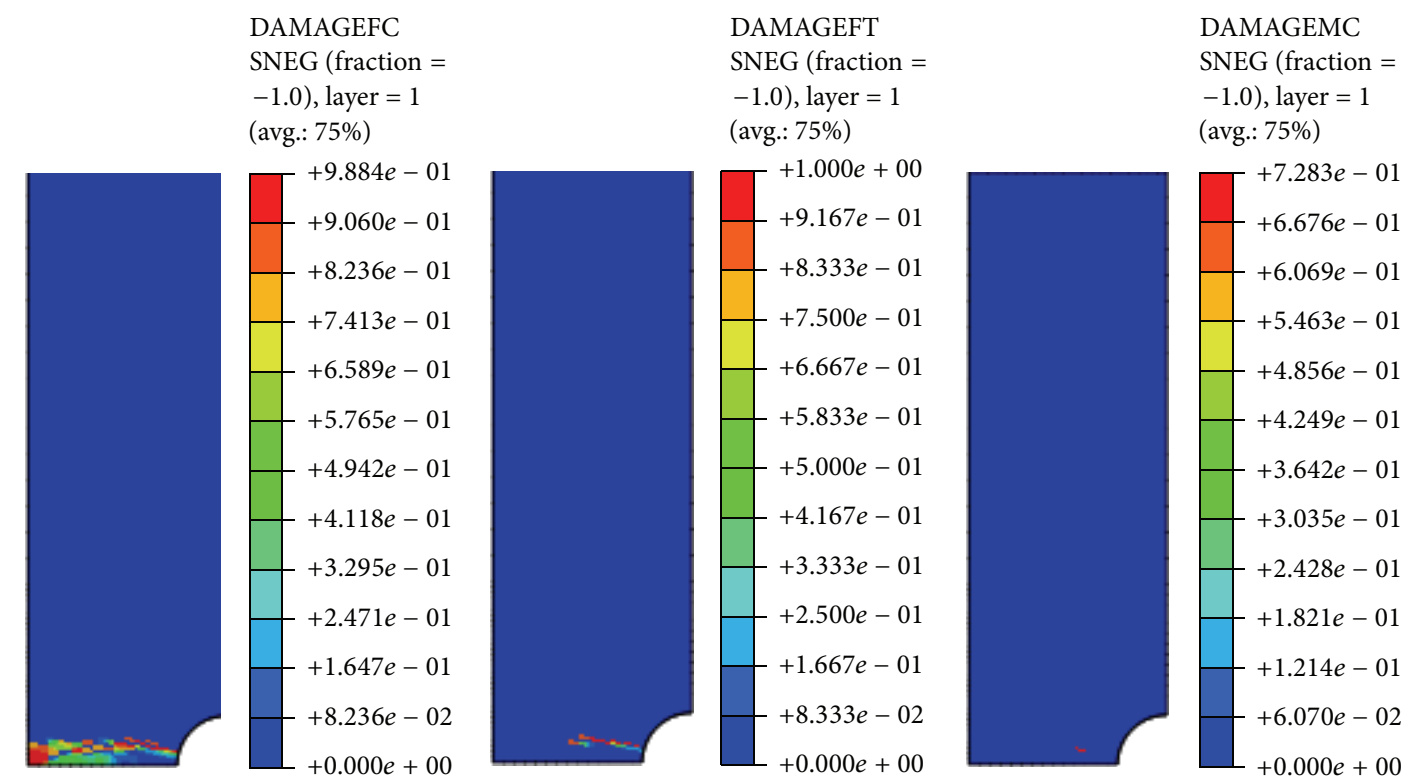

\section{DAMAGEMT}

SNEG (fraction $=$ $-1.0)$, layer $=1$ (avg.: $75 \%)$

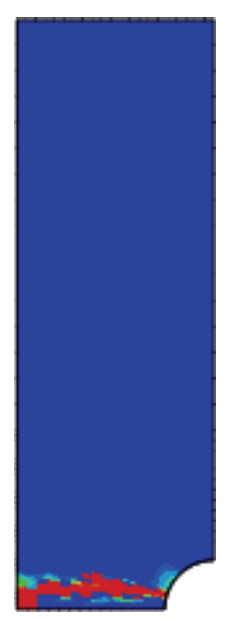

DAMAGEFT

(avg.: $75 \%$ )

$+0.000 e+00$

SNEG $($ fraction $=$ $-1.0)$, layer $=1$ (avg.: $75 \%$ )

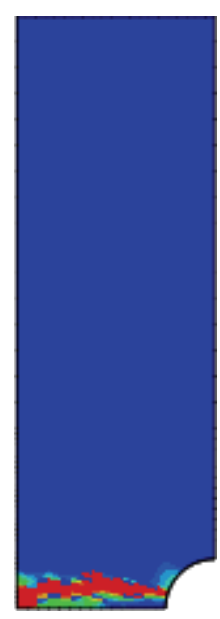

FIGURE 4: The compressive fiber damage (DAMGEFC), tensile fiber (DAMGEFT), compressive matrix damage (DAMAGMT), tensile matrix damage (DAMAGEMT), and shear damage (DAMAGEHR) at integration points.

software. Nodes on the vertical central line of the hole are constrained to move along the vertical " $y$ " direction. Nodes in the horizontal central of the hole are also constrained to move along the horizontal " $x$ " direction. In this study, the laminates ware subjected to the tensile displacement controlled loading. The displacement of the loading control is $1.2 \mathrm{~mm}$. Using constrained equation type in Abaqus, the position of loading is applied at the left upper corner of the model. By doing this, the reaction force and corresponding displacements of the nodes can be conveniently output to this reference point. The laminates are modelled and used conventional shell elements S8R within Abaqus. The shape and dimension of the model are shown in Figure 1 where " $w$ " $=20 \mathrm{~mm}$ is the width of the laminates. The " $d$ " is the diameter of the central hole. " $L$ " $=30 \mathrm{~mm}$ is the length of the laminates. The thickness of the each piece is equal to $0.1635 \mathrm{~mm}$.

\section{Results and Discussions}

The composite laminates are modeled using the finite element analysis and Hashin's initial criteria damage is conducted. Progressive damage analysis and the effect of structure on the strength of the composite laminates are investigated. There are some results discussed and shown as follows.

Predicting the tensile strengths of composite laminates containing a central open-hole, results are presented in Figure 2 . The load dropped down suddenly at the damage 
TABLE 2: Comparison of the tensile strength and displacement of composite laminates.

\begin{tabular}{|c|c|c|c|c|c|c|}
\hline \multirow{2}{*}{$\begin{array}{l}\text { Diameter of the hole } \\
(\mathrm{mm})\end{array}$} & \multicolumn{2}{|c|}{$\begin{array}{c}\text { Structure type } \\
{[0 /-45 / 45 / 90 / 0 /-45 / 45 / 90] \mathrm{s}}\end{array}$} & \multicolumn{2}{|c|}{$\begin{array}{c}\text { Structure type } \\
{[0 / 45 / 0 / 90 / 0 /-45 / 0 / 90] \mathrm{s}}\end{array}$} & \multicolumn{2}{|c|}{$\begin{array}{c}\text { Structure type } \\
{\left[0_{8}\right] \mathrm{s}}\end{array}$} \\
\hline & $\begin{array}{l}\text { Tensile strength } \\
\text { (GPa) }\end{array}$ & $\begin{array}{l}\text { Displacement } \\
(\mathrm{mm})\end{array}$ & $\begin{array}{l}\text { Tensile strength } \\
\text { (GPa) }\end{array}$ & $\begin{array}{l}\text { Displacement } \\
(\mathrm{mm})\end{array}$ & $\begin{array}{c}\text { Tensile strength } \\
(\mathrm{GPa})\end{array}$ & $\begin{array}{l}\text { Displacement } \\
(\mathrm{mm})\end{array}$ \\
\hline$d=1$ & 3.79 & 0.812751 & 2.62 & 0.788365 & 0.93 & 1.10813 \\
\hline$d=2$ & 4.36 & 0.730634 & 3.35 & 0.700396 & 1.14 & 1.04512 \\
\hline$d=4$ & 5.69 & 0.706672 & 3.67 & 0.64677 & 1.28 & 0.973465 \\
\hline$d=6$ & 8.06 & 0.667874 & 3.49 & 0.496342 & 1.52 & 0.952701 \\
\hline
\end{tabular}

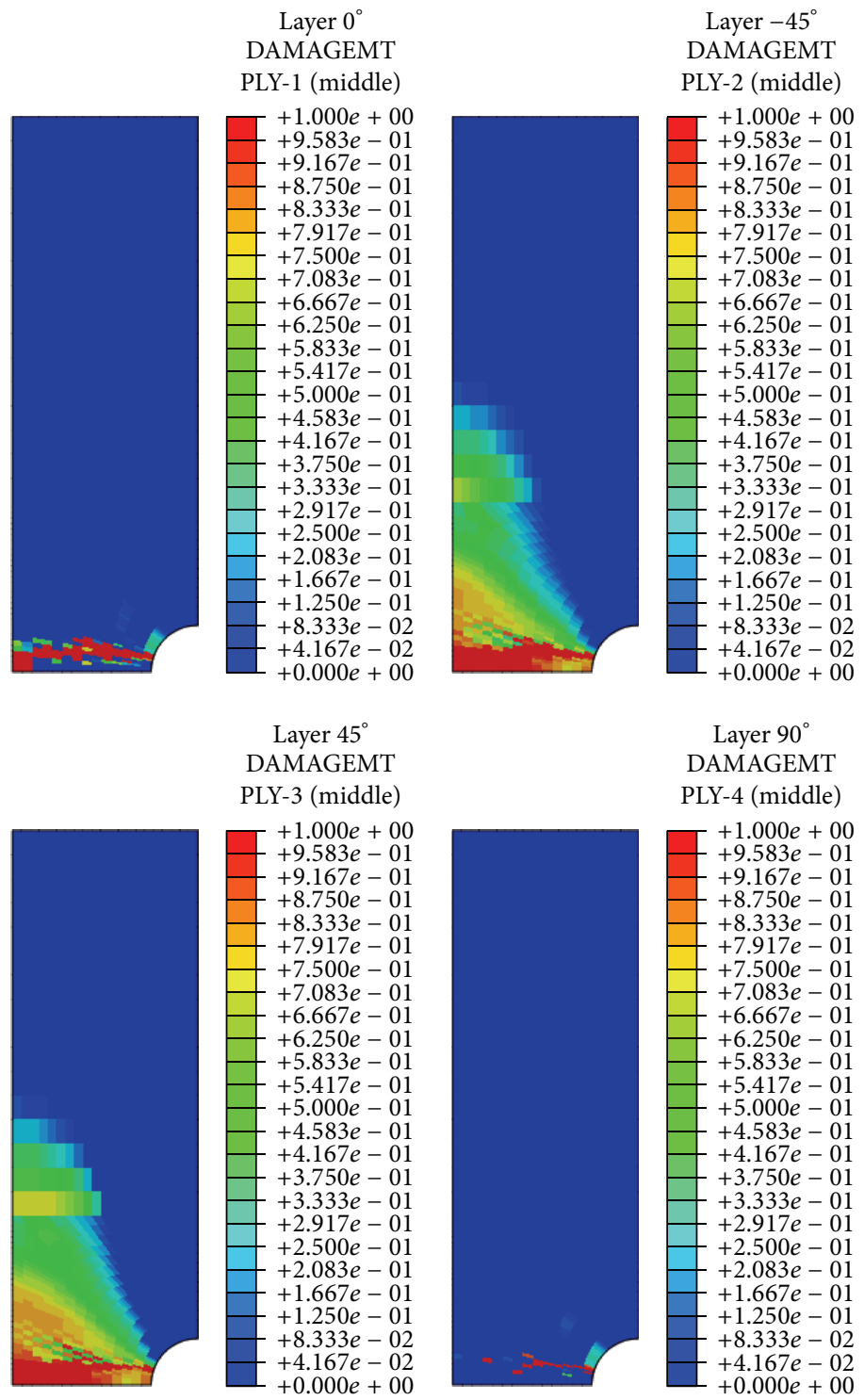

Figure 5: The tensile matrix damage at integration points of the layers $0^{\circ},-45^{\circ}, 45^{\circ}$, and $90^{\circ}$ at $0.04 \%$ train.

initiation point, which indicated that the specimens damaged. It is also clearly shown that load and the strength of the composite laminates decrease with the increasing diameter of the hole. It is very important to notice that the different types of failure are predicted by the loading condition.
Their results indicated that stress concentration at around of the hole is higher, and reduced surrounding areas external edge of the model in the Figure 3. In the Figure 4 the distribution of spectral damage of the fibers reinforced and the matrix of the integration points is plotted. The results 


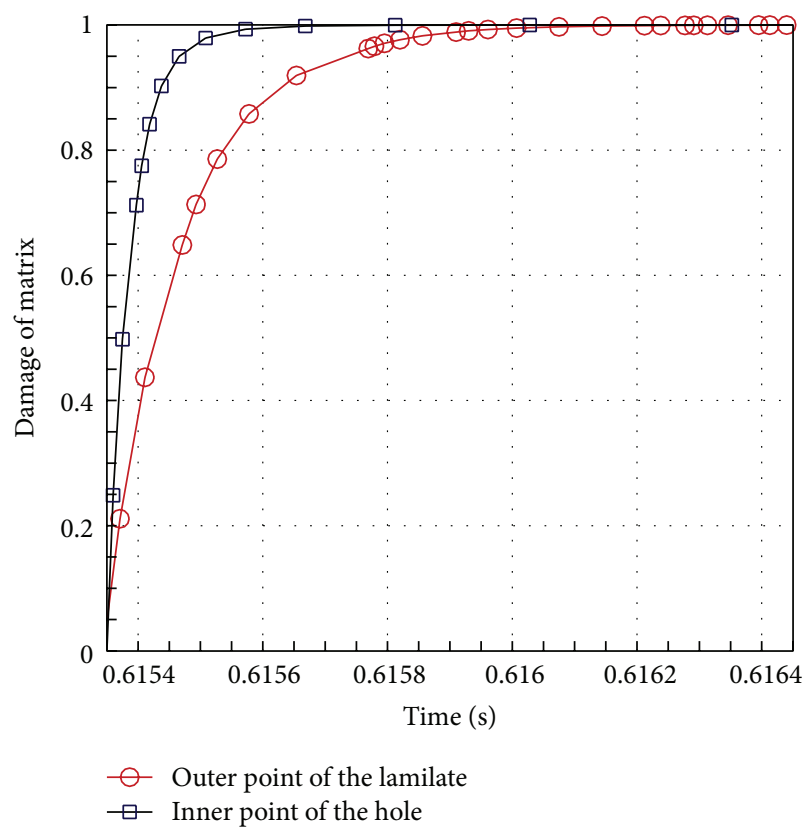

FIGURE 6: Damage rate of the matrix at the inner a point of the hole and outer point of the laminate.

show that the complete failure of the composite laminate occurs around the hole at stress concentration areas. The damage is firstly appeared from the inner edge of the hole, and then it is propagated and developed the external edge of the model. This behavior is likely attributed to be supported by the fibers arranged in the load direction. The appearance of damage of the matrix is earlier than fibers shown in the Figure 5. The stress concentration appeared around the hole that has effects on the tensile strength of the model. The damage of the matrix at stress concentration areas is early appeared and it is faster growth. In Figure 6, the damage rate of the matrix at two corners, the inner corner of the hole faster than the externalcorner of the edge of the model, is indicated.

There are many challenges posed in the design of laminated composite structures. Several parameters, such as layers orientations, selecting layer arrangements, and others, influence the properties of a composite laminate. Therefore, the composite laminate design is a highly iterative process for resolving a combinatorial problem. It is an important and necessary to study laminated composite structure. Three structures $[0 / 45 /-45 / 90 / 0 /-45 / 45 / 90 /] \mathrm{s}$, $[0 / 45 / 0 / 90 / 0 / 45 / 0 / 90] s$, and $\left[0_{8}\right]$ s compared the strength between structures. The relation shift between the reaction force and displacement is shown in Figures 2, 7, and 8. The results are shown in Figures 2, 7, and 8. These results are reported in Table 2 and the plotted by Figure 9. The results of analyses indicated that the initial damage, progressive damage of the composite laminates, and the strength of the laminates not only depend on the diameter of the holes but also depend on the structure of the composite laminates under the same applied load a condition.

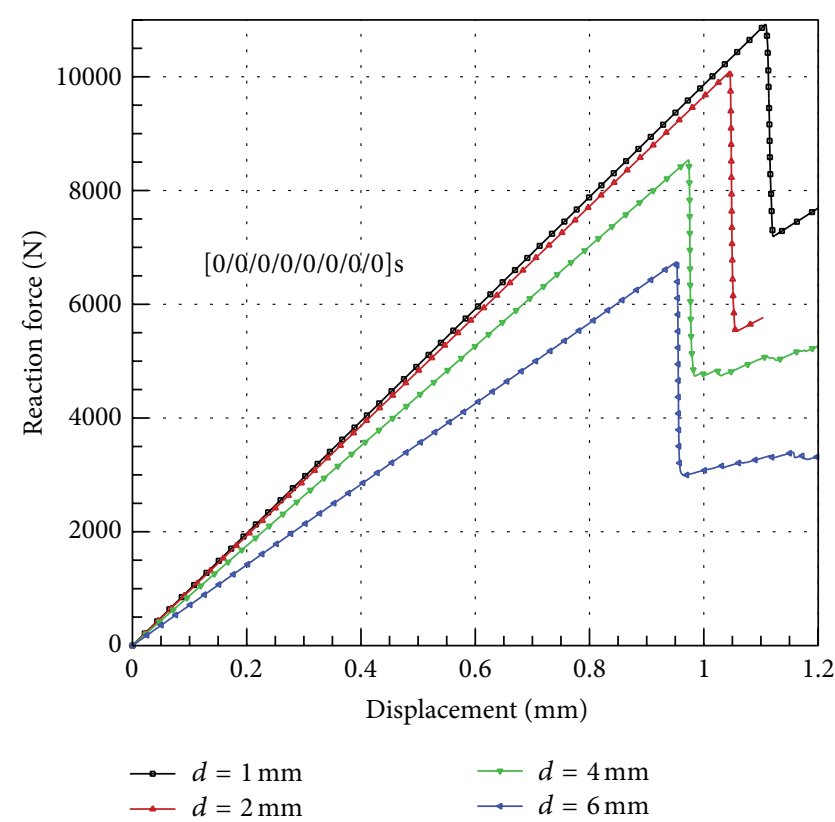

FIGURE 7: Reaction force and displacement curves of $\left[0_{8}\right] \mathrm{s}$ with different diameters of the hole.

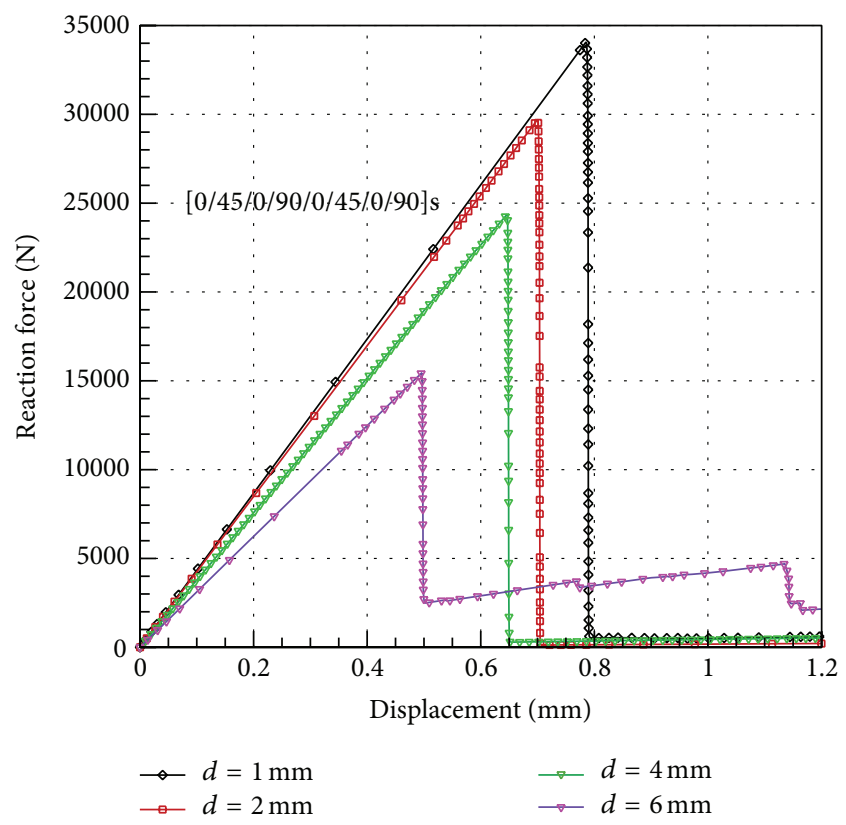

FIGURE 8: Reaction force and displacement curves of [0/45/0/90/0/ $45 / 0 / 90]$ s with different diameters of the hole.

\section{Conclusions}

The composite laminates containing a central open-hole have been developed which is conducted by commercial Abaqus software; several conclusions are drawn as follows.

The prediction of initial damage, progressive damage, and analysis of the effect of structure on strength of composite laminates containing a central open-hole is clearly investigated and confirmed. 


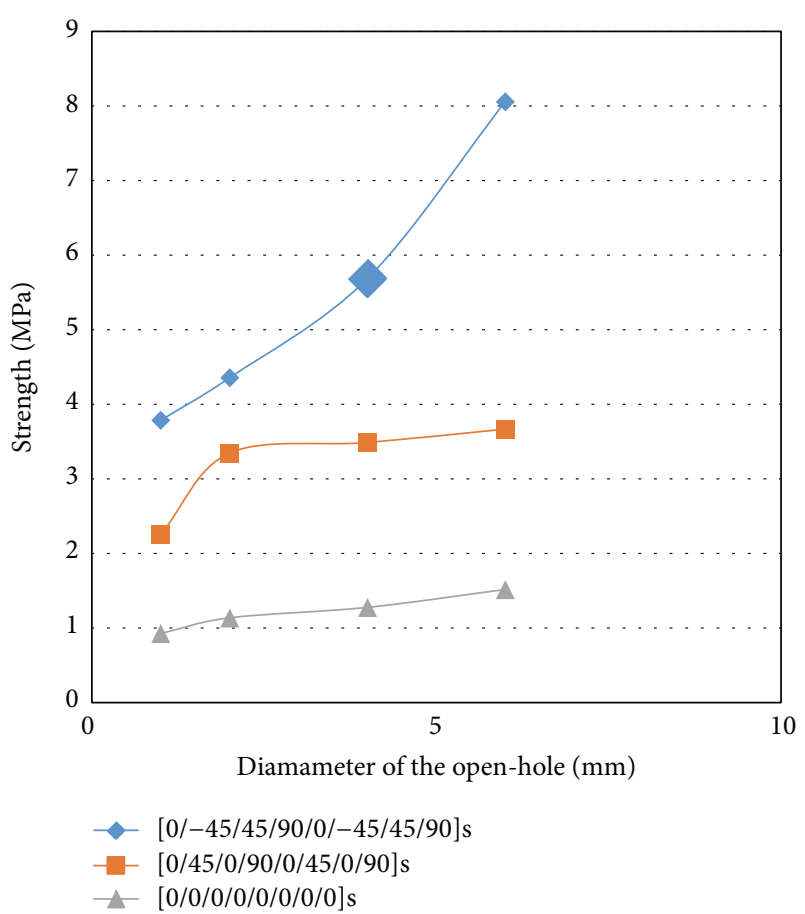

FIGURE 9: Strength of the structures with different diameters of the hole.

Change of the diameter of the central open-hole as well as the change of the structure of composite laminates not only the effect on possible damage, damaging rate, progressive damage but also effects on the strength of the composite laminates is also indicated.

The progressive damage and damage rate of the matrix is confined to the locus of the stress concentration; then the damages grow from the stress concentration areas with further increase of applied load or displacement to reach the tensile strengths.

\section{Conflict of Interests}

The authors of this paper, Chia-Chin Chiang, Liren Tsai, and $\mathrm{Vu}$ Van Thuyet, declare that there is no conflict of interests regarding the publication of this paper.

\section{References}

[1] M. D. Rhodes, M. M. Mikulas, and P. E. McGowan, "Effects of orthotropy and width on the compression strength of graphiteepoxy panels with holes," AIAA Journal, vol. 22, no. 9, pp. 12831292, 1984.

[2] E. J. Barbero, F. A. Cosso, R. Roman, and T. L. Weadon, "Determination of material parameters for Abaqus progressive damage analysis of E-glass epoxy laminates," Composites Part B: Engineering, vol. 46, pp. 211-220, 2013.

[3] J. F. Chen, E. V. Morozov, and K. Shankar, "A combined elastoplastic damage model for progressive failure analysis of composite materials and structures," Composite Structures, vol. 94, no. 12, pp. 3478-3489, 2012.
[4] P. P. Camanho and F. L. Matthews, "A progressive damage model for mechanically fastened joints in composite laminates," Journal of Composite Materials, vol. 33, no. 24, pp. 2248-2280, 1999.

[5] E. G. Guynn and W. L. Bradley, "Measurements of the stress supported by the crush zone in open composite laminates loaded in compression," Journal of Reinforced Plastics and Composites, vol. 8, no. 2, pp. 133-149, 1989.

[6] A. M. Waas, A. JungHyun, and A. R. Khamseh, "Compressive failure of notched uniply composite laminates," Composites Part B: Engineering, vol. 29, no. 1, pp. 75-80, 1998.

[7] M. A. Caminero, M. Lopez-Pedrosa, C. Pinna, and C. Soutis, "Damage monitoring and analysis of composite laminates with an open hole and adhesively bonded repairs using digital image correlation," Composites Part B: Engineering, vol. 53, no. 24, pp. 76-91, 2013.

[8] F. K. Chang, L. Lessard, and J. M. Tang, "Compression response of laminated composites containing an open hole laminates," SAMPE Quarterly, vol. 19, no. 4, pp. 46-51, 1988.

[9] F.-K. Chang and L. B. Lessard, "Damage tolerance of laminated composites containing an open hole and subjected to compressive loadings. Part I. Analysis," Journal of Composite Materials, vol. 25, no. 1, pp. 2-43, 1991.

[10] L. B. Lessard and F.-K. Chang, "Damage tolerance of laminated composites containing an open hole and subjected to compressive loadings. Part II. Experiment," Journal of Composite Materials, vol. 25, no. 1, pp. 44-64, 1991.

[11] K. I. Tserpes, G. Labeas, P. Papanikos, and T. Kermanidis, "Strength prediction of bolted joints in graphite/epoxy composite laminates," Composites Part B: Engineering, vol. 33, no. 7, pp. 521-529, 2002.

[12] Y. Nikishkov, A. Makeev, and G. Seon, "Progressive fatigue damage simulation method for composites," International Journal of Fatigue, vol. 48, no. 5, pp. 266-279, 2013. 


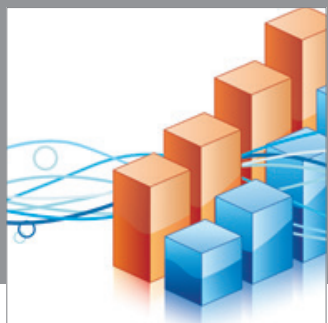

Advances in

Operations Research

mansans

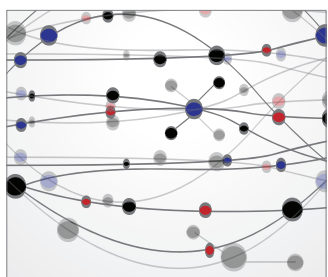

The Scientific World Journal
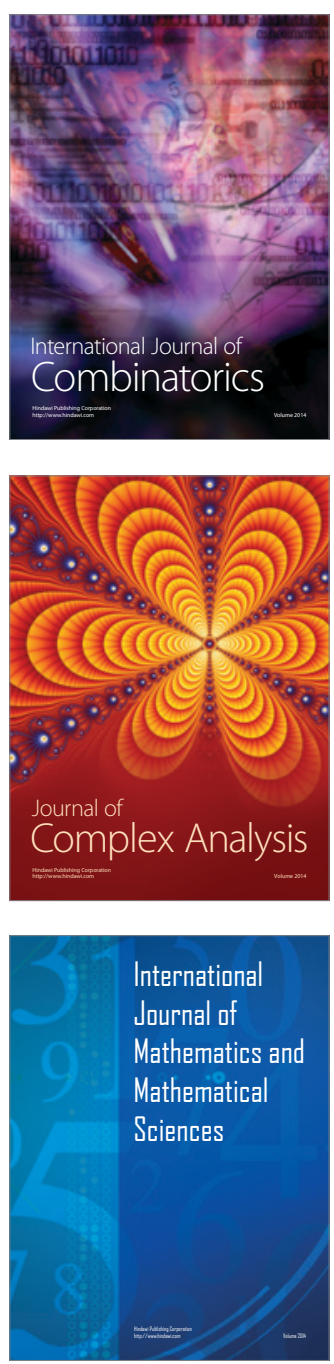
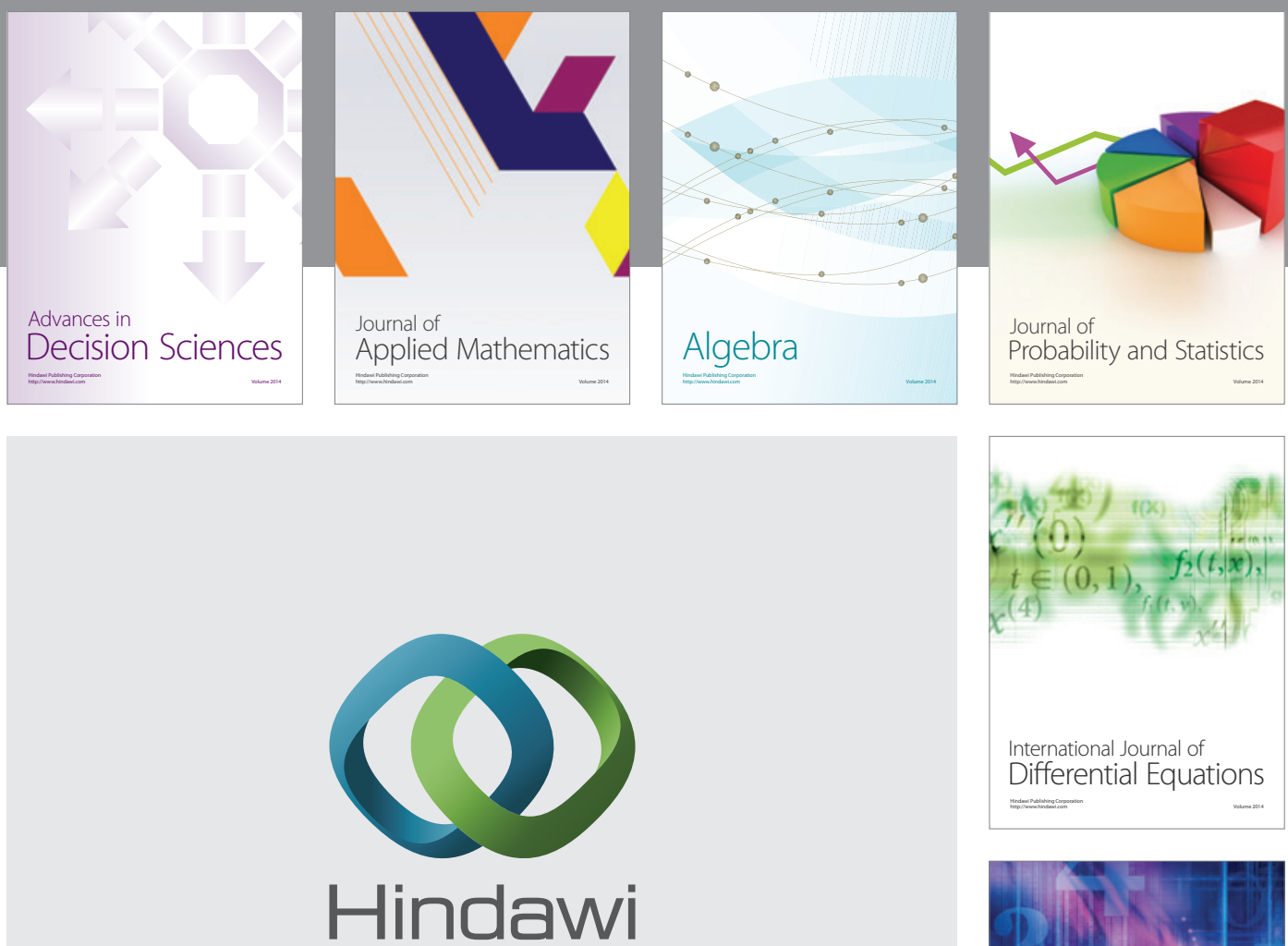

Submit your manuscripts at http://www.hindawi.com
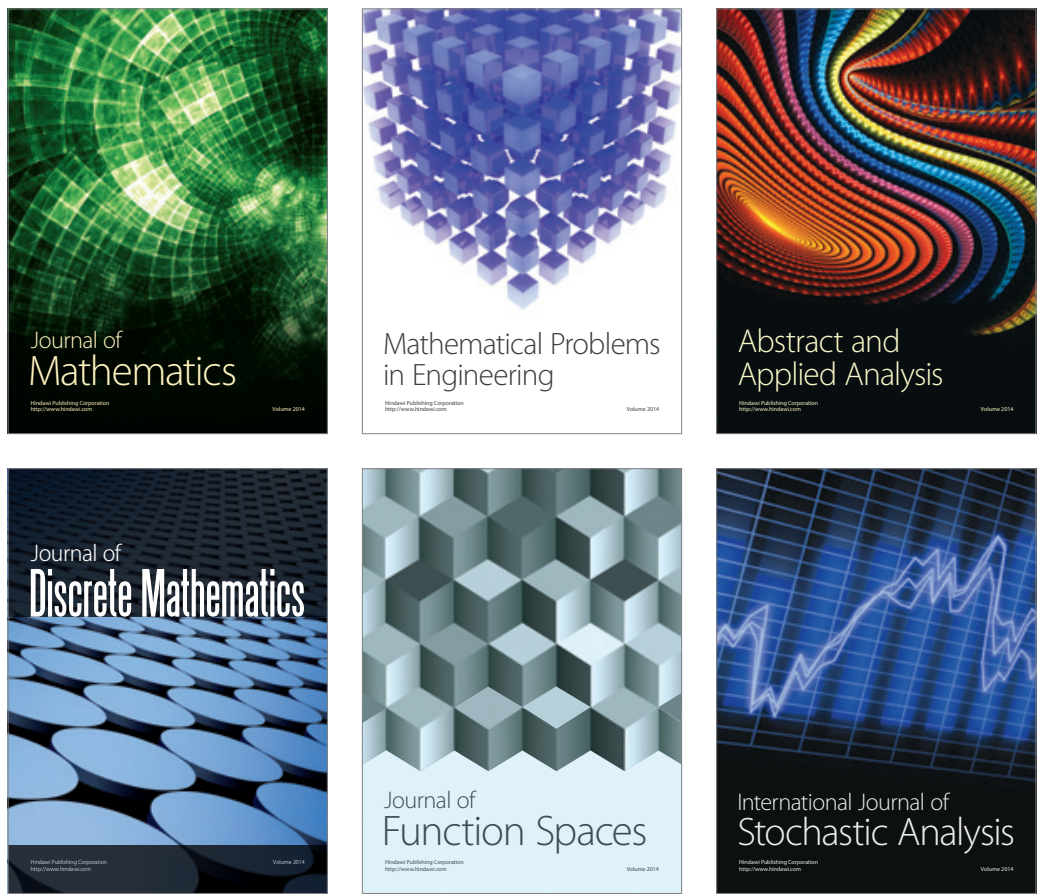

Journal of

Function Spaces

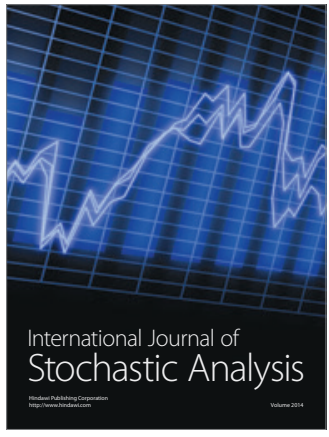

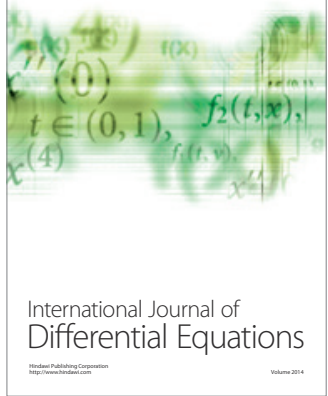
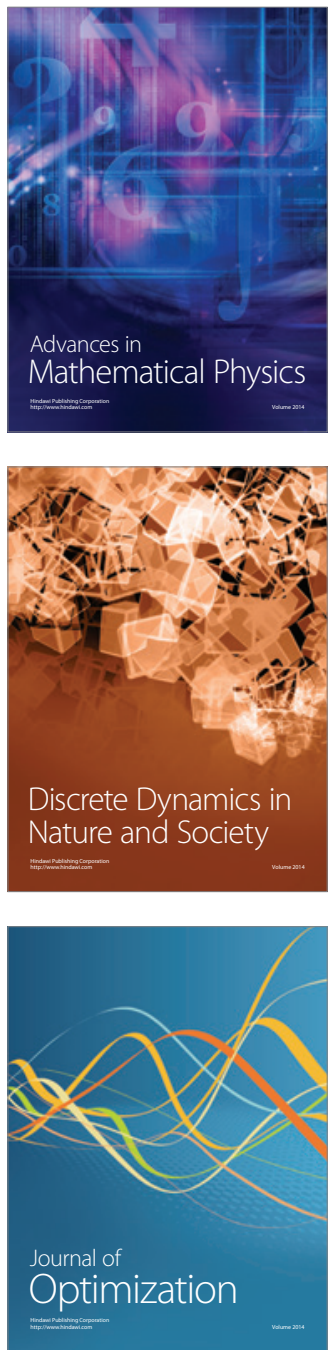